\title{
Alpha-1-antitrypsin globules in the liver and PiM phenotype
}

\author{
J. W. B. BRADFIELD AND W. K. BLENKINSOPP \\ From the Department of Pathology, St. Mary's Hospital, London W2
}

SUMMARY The finding is recorded of typical $a_{1}$-antitrypsin globules, confirmed by immunofluorescence and immunoperoxidase methods, in the hepatocytes of a patient shown to have a normal serum antitrypsin level and normal phenotype (PiM) for $a_{1}$-antitrypsin. The identification of such globules can no longer be regarded as conclusive evidence of an abnormal $\mathrm{a}_{1}$-antitrypsin phenotype.

Some cases of pulmonary emphysema, cirrhosis, or hepatocellular carcinoma are associated with a deficiency of $a_{1}$-antitrypsin in the serum (Sharp, 1976). Microscopically many of these patients have characteristic periodic acid-Schiff (PAS) positive, diastase-resistant globules in the periportal hepatocytes. These globules contain accumulations of antitrypsin antigenically identical with that which is deficient in the serum (Sharp, 1976), and their specificity can be confirmed by immunofluorescence or immunoperoxidase methods using specific antisera against $a_{1}$-antitrypsin and formalin-fixed paraffin-embedded sections of liver.

The normal phenotype for the protease inhibitor system is designated PiM, and the commonest allele associated with deficiency is $P^{Z}$ (Cook, 1974). The liver globules have hitherto been described only in subjects homozygous or heterozygous for the $\mathrm{Pi}^{\mathrm{Z}}$ allele (Martin et al., 1976), the apparent exception in a patient with emphysema and the phenotype PiSS (Lieberman et al., 1972) being subsequently identified as PiSZ (Cook, 1976). Comparison of the frequency of occurrence of the globules in otherwise normal livers with the frequency of occurrence of the phenotype PiMZ suggests that probably all subjects with one or two $P i^{Z}$ alleles have the characteristic globules in the liver (Eriksson et al., 1975; Blenkinsopp and Haffenden, 1977). The homozygous PiZZ state, found in $0.03 \%$ of the population of England and Wales, is associated with a high risk or neonatal or adult liver disease; most subjects with the heterozygous PiMZ state $(3 \%$ of the population) have no liver disease.

The diagnosis of $a_{1}$-antitrypsin deficiency can be made by estimation of the serum level, by serum analysis of the phenotype, or by identification of the

Received for publication 4 October 1976 liver globules. As a $a_{1}$-antitrypsin is an acute phase reactant the serum level can rise to within the normal 3 range in subjects with deficiency (Triger et al., 1976); the serum level is therefore often not a reliable $\vec{\varphi}$ indicator of deficiency. Phenotype analysis can be performed by several methods, some of which, such as starch gel electrophoresis, will not demonstrate a $P^{2} Z$ allele if relatively little of the $\mathrm{Z}$ type antitrypsin is present unless antigen-antibody crossed electrophoresis is used; other pitfalls are described by Cook (1975). Isoelectric focusing provides a reliable assessment of phenotype, including the presence of a $\mathrm{Pi}^{Z}$ allele, but is not available except as a supraregional service. Triger et al. (1976) have therefore suggested that one of the most satisfactory ways of diagnosing a $a_{1}$-antitrypsin deficiency is by the identification of typical globules in the hepatocytes; these authors have described typical PAS positive globules which were negative on immunofluorescence and immunoperoxidase staining using an antiserum to human $a_{1}$-antitrypsin in two subjects with normal PiM phenotype, and therefore consider that confirmation by immunohistology is necessary. There is no other report of typical PAS positive, diastase-resistant but immunologically negative $N$ globules in hepatocytes, nor is there a report hitherto $N$ of typical PAS positive, diastase-resistant, immuno- N logically positive globules in a patient with normal $\omega$ (PiM) phenotype-the subject of this paper.

\section{Case report}

A man aged 79 years was admitted with severe acute pancreatitis. No cause was identified and $\cong$ alcohol was not implicated. At operation a liver $\stackrel{\complement}{\complement}$ biopsy was taken and this showed abundant typical PAS positive, diastase-resistant globules in peri- 8 
portal hepatocytes (Figure) but no other abnormality apart from a modest excess of fat.

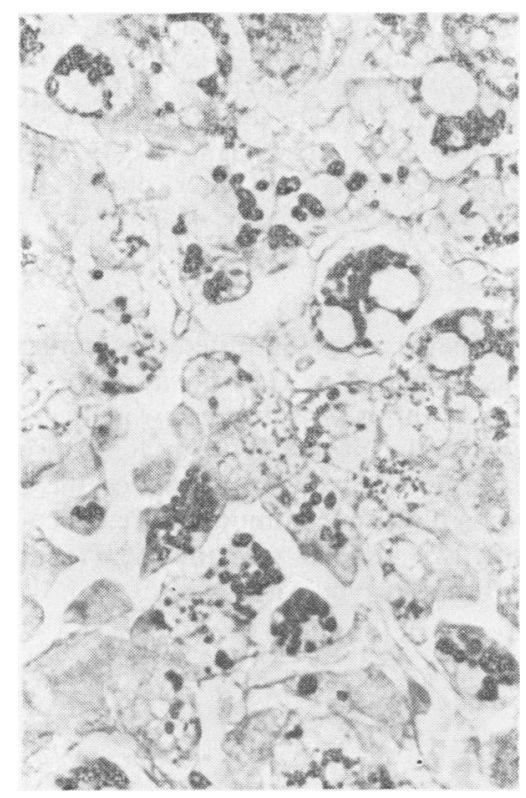

Figure $a_{1}$-Antitrypsin globules in periportal hepatocytes. PAS/diastase $\times 220$

The globules were identified as a $a_{1}$-antitrypsin by specific antiserum (Behringwerke) applied to the sections and demonstrated by both immunofluorescent and immunoperoxidase methods (Blenkinsopp and Haffenden, 1977) using appropriate controls. Serum taken one day after operation gave an antitrypsin level of $2.3 \mathrm{~g} / \mathrm{l}$ by the Mancini technique using agar diffusion plates (normal range 2-4 g/l). Twelve days later the patient died: postmortem examination confirmed the pancreatitis and the liver histology showed the same appearances as in the biopsy, again with immunological confirmation of the $a_{1}$-antitrypsin globules.

We considered that the patient's phenotype was probably PiMZ, and because of the acute phase reaction the normal serum level of antitrypsin was expected. To confirm the diagnosis antemortem serum (stored at $-20^{\circ} \mathrm{C}$ ) and postmortem blood were sent to Dr Cook for phenotyping: the two antemortem samples and the single postmortem sample all showed PiM only, with no evidence of an abnormal allele, on starch gel electrophoresis. As this was entirely unexpected, the specimens were sent on to the Supraregional Specific Protein Reference Unit (Sheffield) for phenotyping by iso- electric focusing: this confirmed that only PiM was present.

The immunofluorescent and immunoperoxidase identification of $a_{1}$-antitrypsin in the globules was therefore repeated on sections from further blocks of both the biopsy and the postmortem specimens using a specific antiserum of different manufacture (Dakopatts): the results were again positive. Sections from postmortem liver blocks were sent to Professor McGee and to Dr Ray, and both reported positive identification of $a_{1}$-antitrypsin in the globules.

\section{Discussion}

Hitherto the finding of typical $a_{1}$-antitrypsin globules in hepatocytes, with immunohistological confirmation, has been taken as conclusive evidence of an abnormal protease inhibitor phenotype, probably with a $P_{i} z$ allele (Martin et al., 1976). The present case is the first recorded example of the presence of typical globules in a subject with apparently normal (PiM) phenotype. The documentation of both the immunohistological identification and the phenotyping, each on multiple samples and in more than one laboratory, appears established beyond reasonable doubt. The possibility of error in identification of the specimens appears extremely remote, since multiple samples taken at different times gave the same results.

The diagnosis of an abnormal a $a_{1}$-antitrypsin phenotype has thus become more difficult. It is known that abnormal phenotypes occur without globules in the hepatocytes, as in Pi- - (Feldmann et al., 1975) and in PiS phenotypes without $Z$ (Gordon et al., 1972), and that an abnormal phenotype can be associated with normal serum levels of a -antitrypsin (Triger et al., 1976). It now appears that typical globules can occur in the hepatocytes with a normal phenotype. The similar figures found for frequency of the $\mathrm{Pi}^{Z}$ allele in the population (3\%) (Cook, 1974) and for frequency of globules in otherwise normal livers $(3.6 \%)$ (Blenkinsopp and Haffenden, 1977) suggest that the combination of globules and normal phenotype is probably a rare occurrence.

It is a pleasure to record our gratitude to $\mathrm{Mr}$ G. $\mathbf{P}$. Haffenden for technical assistance, to Mrs J. McMurray for the serum antitrypsin level, to Professor J. O'D. McGee (Oxford) and Dr M. B. Ray (Leuven) for the identification of the globules, and to Dr P. J. L. Cook (London) and Dr M. E. Spencer (Sheffield) for phenotyping.

\section{References}

Blenkinsopp, W. K. and Haffenden, G. P. (1977). 
Alpha-1-antitrypsin bodies in the liver. Journal of Clinical Pathology, 30, 132-137.

Cook, P. J. L. (1974). Genetic aspects of the Pi system. Postgraduate Medical Journal, 50, 362-364.

Cook, P. J. L. (1975). The genetics of $a_{1}$-antitrypsin: a family study in England and Scotland. Annals of Human Genetics, 38, 275-287.

Cook, P. J. L. (1976). Personal communication.

Eriksson, S., Moestrup, T., and Hagerstrand, I. (1975). Liver, lung and malignant disease in heterozygous (PiMZ) a 1-antitrypsin deficiency. Acta Medica Scandinavica, 198, 243-247.

Feldmann, G., Martin, J.-P., Sesboue, R., Ropartz, C., Perelman, R., Nathanson, M., Seringe, P., and Benhamou, J.-P. (1975). The ultrastructure of hepatocytes in alpha-1-antitrypsin deficiency with the genotype Pi- -. Gut, 16, 796-799.

Gordon, H. W., Dixon, J., Rogers, J. C., Mittman, C., and Lieberman, J. (1972). Alpha1-antitrypsin (A1AT) accumulation in livers of emphysematous patients with A1AT deficiency. Human Pathology, 3, 361-370.

Lieberman, J., Mittman, C., and Gordon, H. W. (1972). Alpha1-antitrypsin in the livers of patients with emphysema. Science, 175, 63-65.

Martin, J. P., Charlionet, R., Sesboue, R., and Ropartz, C. (1976). Alpha1-antitrypsin deficiency (Letter). Lancet, 1, 434.

Sharp, H. L. (1976). The current status of a-1-antitrypsin, a protease inhibitor, in gastrointestinal disease. Gastroenterology, 70, 611-621.

Triger, D. R., Millward-Sadler, G. H., Czaykowski, A. A., Trowell, J., and Wright, R. (1976). Alpha-1antitrypsin deficiency and liver disease in adults. Quarterly Journal of Medicine, 45, 351-372.

\section{Addendum}

Since this paper was submitted for publication a report has appeared in Gastroenterology, 1976, 71, 646-651 (a-1-Antitrypsin deficiency in liver disease: the extent of the problem) from R. L. Fisher, L. Taylor, and S. Sherlock, which notes the presence of PAS-positive and immunofluorescence-positive globules in two patients without the $P^{Z}{ }^{Z}$ allele-one PiMS and one Pi type M. 